\title{
Biomechanics of Resistance Artery Wall Remodeling in Angiotensin-II Hypertension and Subsequent Recovery
}

\author{
György L. Nádasy ${ }^{a} \quad$ Szabolcs Várbírób ${ }^{b}$ Mária Szekeres ${ }^{c}$ Adrienn Kocsis $^{a}$ \\ Béla Székács ${ }^{d, e}$ Emil Monos $^{a}$ Márk Kollai $^{a}$ \\ Departments of ${ }^{\mathrm{a} C l i n i c a l}$ Research and Human Physiology, ${ }^{\mathrm{b}}$ Obstetrics and Gynecology (2nd Department), \\ 'Physiology, and ${ }^{d}$ Internal Medicine (2nd Department) and Geriatrics, Semmelweis University, and \\ e Department of Geriatrics, St. Imre Hospital, Budapest, Hungary
}

\section{Key Words}

Hypertension • Vascular biomechanics • Angiogenesis • Resistance artery · Angiotensin-II - Arterial remodeling • Aging $\cdot$ Vascular recovery

\begin{abstract}
Background/Aims: To identify the relationship between systemic and local hemodynamics, as well as segmental biomechanical properties in a musculocutaneous resistance artery during angiotensin-II hypertension and its recovery. Methods: Rats were infused with angiotensin-Il using implanted osmotic minipumps (ALZET 2ML4, $150 \mathrm{ng} / \mathrm{kg} / \mathrm{min}$ ) for 4 weeks. Measurements were made either immediately following infusion or after an additional 4-week recovery period. Parallel controls were created. Segmental geometry and blood flow were determined in vivo on microsurgically exposed segments of the saphenous arterial branch (350 $\mu \mathrm{m})$. Pressure-radius plots of excised cylindrical segments were recorded by pressure arteriography. Results: Eutrophic hypertensive wall remodeling developed, with reduced passive radius, increased wall thickness, elevated low-stress elastic modulus, reduced norepinephrine contraction, and reduced endothelium-mediated dilation. Relaxed wall geometry fully healed in 4 weeks of recovery, but an increased contractility and a reduced in vivo lumen persisted. Region-
\end{abstract}

al hemodynamic resistance correlated positively with systemic arterial pressure and wall thickness in vivo, and negatively with in vivo lumen size throughout these studies. Conclusion: A partial recovery of the biomechanical parameters was found. Healing of eutrophic hypertensive remodeling of the resistance artery wall is a complex biomechanical process, not a simple reversal of the original pathological sequel.

Copyright $\odot 2010$ S. Karger AG, Basel

\section{Introduction}

Sustained hypertension is accompanied by remodeling of the wall of resistance arteries. At the segmental level, this remodeling is characterized by a narrowed lumen [1-13], increased wall thickness [1-15] (either with increased $[2,8,10,13,14,16]$ or unaltered $[2,4,8,9]$ wall mass), increased rigidity of the wall in certain pressure ranges $[5,10,17-22]$, alterations in myogenic and druginduced contractility [7, 23, 24], and reduced endothelial dilation $[6,8,25]$. Complex network changes can also be seen to result in vascular rarefaction $[26,27]$. Hypertensive remodeling plays an essential role in the stabilization of the elevated hemodynamic resistance, and thus in stabilization of the disease $[1,2,4,7,10,11,28]$. From a clin-

\section{KARGER}

Fax +41613061234 E-Mail karger@karger.ch www.karger.com

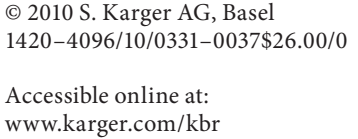

Sen. Assoc. Prof. G.L. Nádasy, MD, PhD

Clinical Research Department and Department of Human Physiology

Semmelweis University, Tuzolto Str. 37-47

HU-1094 Budapest (Hungary)

Tel. +36 121002 90/60317, Fax +36133431 62, E-Mail nadasy@elet2.sote.hu 
ical point of view, it is of the utmost importance to determine how remodeled resistance arteries will respond when blood pressure is reduced. For different types of hypertension and for different types of vessels, different outcomes have been reported, such as full recovery $[8,24$, $29]$ partial recovery $[6,15,30-34]$, and recovery dependent on the type of treatment $[4,11,12,20,29,35-38]$. The hemodynamic resistance of a cylindrical vascular segment is determined by a single factor, its inner radius, which is controlled by a complex interplay between morphological caliber, wall thickness, wall elasticity, and smooth muscle contractility, as well as by levels of blood pressure, local blood flow, vasoactive factors, and neural stimulation. As a result, the same in vivo caliber can be produced in different ways, and the same remodeled artery will feature different in vivo calibers in different situations. Therefore, for a full understanding of the events, we have to combine in vivo hemodynamic measurements with an analysis of segmental biomechanics [39]. Such an analysis cannot be found in the existing literature, and even less is known about the recovery process.

Reversible hypertension was induced through a 4week infusion of angiotensin-II (ATII, $150 \mathrm{ng} / \mathrm{min} / \mathrm{kg}$ ) in the rat $[40,41]$. Locally produced ATII is assumed to be responsible, at least partly, for the resistance artery alterations in human essential hypertension disease [11, $40-44]$. In the present study, we used parallel in vivo hemodynamic and in vitro pressure arteriographic studies to analyze how the in vivo caliber of a musculocutaneous resistance artery depends on angiogenic remodeling of morphological geometry, elasticity, and contractility, as well as on the contractile state during ATII-induced hypertension and subsequent recovery.

\section{Methods}

\section{Chronic ATII Infusion}

Adult male Sprague-Dawley rats, weighing 230-300 g and 8 weeks old at the start of the study, were used (Charles Rivers). In the first group (4ATII, $\mathrm{n}=13$ ), under Nembutal anesthesia (Sanofi, $45 \mathrm{mg} / \mathrm{kg}$ i.p.), osmotic minipumps (Alzet type 2ML4) were inserted surgically under the skin of the back. ATII acetate (Sigma) was infused for 4 weeks, at a continuous rate of $2.4 \mu \mathrm{g} / \mathrm{h}$ $(145.5 \pm 6.7 \mathrm{ng} / \mathrm{min} / \mathrm{kg}$ drug infusion rate, decreasing to $87.5 \pm$ $4.4 \mathrm{ng} / \mathrm{min} / \mathrm{kg}$ at the end of the 4 -week infusion period with the weight gain of the animals). At the end of the fourth week, the animals were reanesthetized, and in vivo hemodynamic and in vitro biomechanical measurements were taken. Animals in the second group $(4 \mathrm{C}, \mathrm{n}=11)$ were sham-operated controls. Rats of the third group ( $4 \mathrm{ATII}+4 \mathrm{C}, \mathrm{n}=14$ ) were treated similarly to the first group until the end of the fourth week, when they were reanesthetized and the osmotic minipumps were removed. After 4 additional weeks under control conditions (recovery), the same measurements were made as in the first group. The fourth group $(8 \mathrm{C}, \mathrm{n}=14)$ provided the age-matched sham-operated controls for the third group. The experiments were performed in accordance with the current National, European and US animal care regulations.

Hemodynamic Measurements and in vivo Geometry

Carotid artery blood pressure was monitored in Nembutal-induced anesthesia using an electromanometer. In vivo outer diameter of the saphenous artery branch was measured by video microscopy on microsurgically exposed segments. Segmental blood flow was determined ultrasonographically (Transonic T106 equipped with $1 \mathrm{R}$ flowprobe). Cardiac output was estimated in the ascending aorta (Transonic T106 with 3RS flowprobe). Hemodynamic resistance (systemic and local: $\mathrm{R}$ ) was computed as $\mathrm{R}=\mathrm{p} / \mathrm{Q}$, where $\mathrm{p}$ is the mean arterial pressure $(\mathrm{mm} \mathrm{Hg})$ and $\mathrm{Q}$ is the ultrasonographically measured flow in the vessel ( $\mathrm{ml} / \mathrm{min})$.

In vitro Biomechanical Test (Pressure Microarteriography)

Segments of the left saphenous artery were excised for in vitro pressure microarteriography. The segments were extended to their in vivo lengths and mounted in a glass-bottomed superfused tissue bath (Experimetria) containing $\mathrm{pH}$-balanced thermostated normal Krebs-Ringer physiological salt solution. The segments were pressurized with saline using a pressure reservoir and an infusion-withdrawal flow pump (Harvard Apparatus). After $30 \mathrm{~min}$ of incubation at $50 \mathrm{~mm} \mathrm{Hg}$ intraluminal pressure, the pressure was changed in consecutive cycles between 0 and $200 \mathrm{~mm} \mathrm{Hg}$ at an approximate rate of $1 \mathrm{~mm} \mathrm{Hg} / \mathrm{s}$. The outer diameter of the segments was continuously and automatically measured using an automated optical microarteriography system developed in our department. The microscopic video image of the vessel segment was generated on the screen (Phillips analog video-camera and monitor, $\times 174$ screen magnification), and a minicomputer evaluated the light intensity along a preset horizontal line of the screen. Two marker spots were automatically positioned at the outer contours of the segment, and its outer diameter was continuously measured. Inner diameters were determined occasionally by manual settings of the 2 calipers, and were used to compute the cross-section of the wall. Because of the limited alterations in specific weight, alterations in the cross-section of the wall best characterize alterations in wall mass. Pressurediameter plots were taken in normal Krebs-Ringer solution to test spontaneous tone and in the same solution with $10 \mu \mathrm{mol} / \mathrm{l}$ norepinephrine added to induce maximal contraction. To test the extent of endothelial dilation, $10 \mu \mathrm{mol} / \mathrm{l}$ acetylcholine was added to the solution. Finally, a calcium-free solution was added to record pressure-diameter plots of fully relaxed vessel segments. Inner radii and wall thicknesses were computed supposing isovolumetry of wall material. Tangential stress was computed using the Laplace-Frank equation, $\sigma=p \times r_{i} / h$, where $\sigma$ is the tangential stress, $p$ is the transmural pressure, $r_{i}$ is the inner radius, and $\mathrm{h}$ is the wall thickness. Incremental distensibility (D) was computed as $\mathrm{D}=\Delta \mathrm{V} /\left(\Delta \mathrm{pV}_{0}\right)$, where $\Delta \mathrm{V}$ is the change of lumen volume from an initial value of $\mathrm{V}_{0}$ if a pressure increase of $\Delta \mathrm{p}$ is applied. The incremental tangential elastic modulus $\left(\mathrm{E}_{\mathrm{inc}}\right)$ was computed using the formula $E_{\text {inc }}=2\left[\mathrm{r}_{\mathrm{o}} \mathrm{r}_{\mathrm{i}}{ }^{2} /\left(\mathrm{r}_{\mathrm{o}}{ }^{2}-\mathrm{r}_{\mathrm{i}}{ }^{2}\right)\right] \times$ $\left(\Delta \mathrm{p} / \Delta \mathrm{r}_{\mathrm{o}}\right)$ where $\mathrm{r}_{\mathrm{o}}$ and $\mathrm{r}_{\mathrm{i}}$ are the actual values of outer and inner radii and $\Delta \mathrm{r}_{\mathrm{o}}$ is the change in outer radius induced by an altera- 


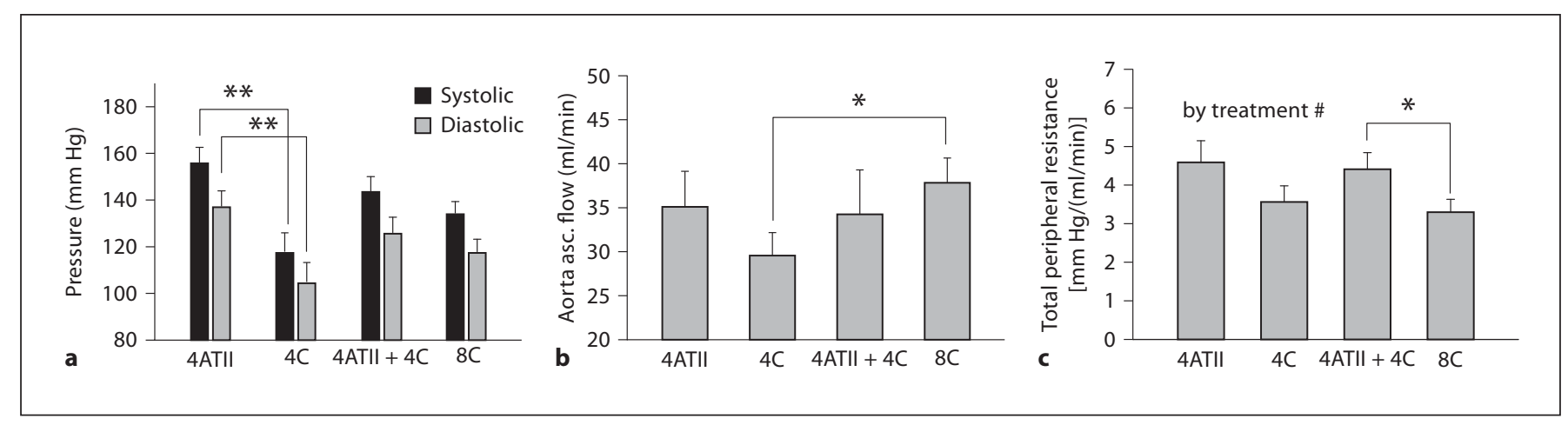

Fig. 1. Systemic hemodynamics. Alterations in ATII-induced hypertension and subsequent recovery. a Systolic and diastolic arterial pressures. b Cardiac output. c Total peripheral resistance. ${ }^{*} \mathrm{p}<0.05 ;{ }^{*} \mathrm{p}<0.01$ (1-way ANOVA); ${ }^{*} \mathrm{p}<0.05$ (2-way ANOVA).

tion of intraluminal pressure of $\Delta \mathrm{p}$ [30]. Contraction was characterized as shortening of the inner radius relative to the fully relaxed state (active strain): contraction $=\left(\mathrm{r}_{\text {irel }}-\mathrm{r}_{\text {icontr }}\right) /$ $r_{\text {irel }}$, where $r_{\text {irel }}$ and $r_{\text {icontr }}$ were the relaxed and contracted inner radii, respectively. Biomechanical parameters were plotted against intraluminal pressure (isobaric comparison) with the exception of the log elastic modulus - tangential stress plots.

\section{Statistical Analysis}

All parameters were expressed as means \pm SEM. One-way and two-way ANOVA tests were used for comparisons (the exact type of statistical test applied in each individual case is given later). The interdependence of 21 hemodynamic and biomechanical parameters in all possible pairings of pooled data was analyzed computing the significance level of their Pearson's correlation (52 animals, 210 correlations). Probability levels of $\mathrm{p}<0.05$ were accepted as statistically significant.

\section{Results}

\section{Systemic Hemodynamics}

Four and 8 weeks are considerably long periods when compared with the short life cycle of the rat. ATII infusion was initiated at the age of 8 weeks (young adult, mature rats with body weights of $271 \pm 4 \mathrm{~g}$ ) and finished at 12 weeks ( $457 \pm 9$ and $427 \pm 10 \mathrm{~g}$ for ATII-infused and control rats, respectively). The recovery period ended at age 16 weeks (ATII-infused: $506 \pm 9$ g; controls: $522 \pm$ $11 \mathrm{~g})$. Systemic hemodynamics in the 4 groups of rats are shown in figure 1.

Mean arterial pressure of ATII-infused animals rose to $142 \pm 6 \mathrm{~mm} \mathrm{Hg}$ as compared to $106 \pm 7 \mathrm{~mm} \mathrm{Hg}$ in age-matched controls $(\mathrm{p}<0.05)$. Four weeks after terminating the infusion, there was a partial recovery and the mean arterial pressure of originally treated animals did not differ significantly from that of untreated agematched controls (133 \pm 9 vs. $120 \pm 5 \mathrm{~mm} \mathrm{Hg}$, n.s.).

Cardiac output increased with age in control animals $(\mathrm{p}<0.05)$, and ATII infusion did not alter this parameter significantly. This age-induced elevation of cardiac output was absent in ATII-treated animals during the recovery period.

Total peripheral resistance significantly rose as a consequence of ATII treatment $(\mathrm{p}<0.001)$. Animals originally infused still had higher total peripheral resistance values after 4 weeks of recovery than their non-infused age-matched counterparts $[4.6 \pm 0.4$ vs. $3.3 \pm 0.3 \mathrm{~mm}$ $\mathrm{Hg} /(\mathrm{ml} / \mathrm{min}), \mathrm{p}<0.05]$.

\section{Local Hemodynamics and in vivo Geometry}

Segmental saphenous artery flow was not significantly altered by ATII infusion $(1.1 \pm 0.3$ vs. $0.9 \pm 0.2 \mathrm{ml} /$ min, n.s; fig. 2a), but age between 12 and 16 weeks significantly reduced this parameter $(0.35 \pm 0.06 \mathrm{ml} / \mathrm{min}$ in 8-week controls, $\mathrm{p}<0.05$ ).

In vivo inner radii of infused and non-infused rats did not differ (176 \pm 25 vs. $162 \pm 30 \mu \mathrm{m}$, n.s; fig. $2 \mathrm{~b})$, but there was a reduction with age $(\mathrm{p}<0.002)$. A more pronounced in vivo narrowing of the vascular lumen developed in the originally ATII-infused animals (121 $\pm 9 \mu \mathrm{m}$ in $8 \mathrm{C}$ and $72 \pm 9 \mu \mathrm{m}$ in $4 \mathrm{ATII}+4 \mathrm{C}, \mathrm{p}<0.05)$.

Any further analysis should take into consideration that in vivo tone is substantial in this musculocutaneous small artery (fig. 2c). Control basal tone in anesthetized animals was $48 \pm 8 \%$, not significantly different from ATII-treated ones $(59 \pm 8 \%)$. In ATII-treated animals, however, there was a pronounced further elevation of in 


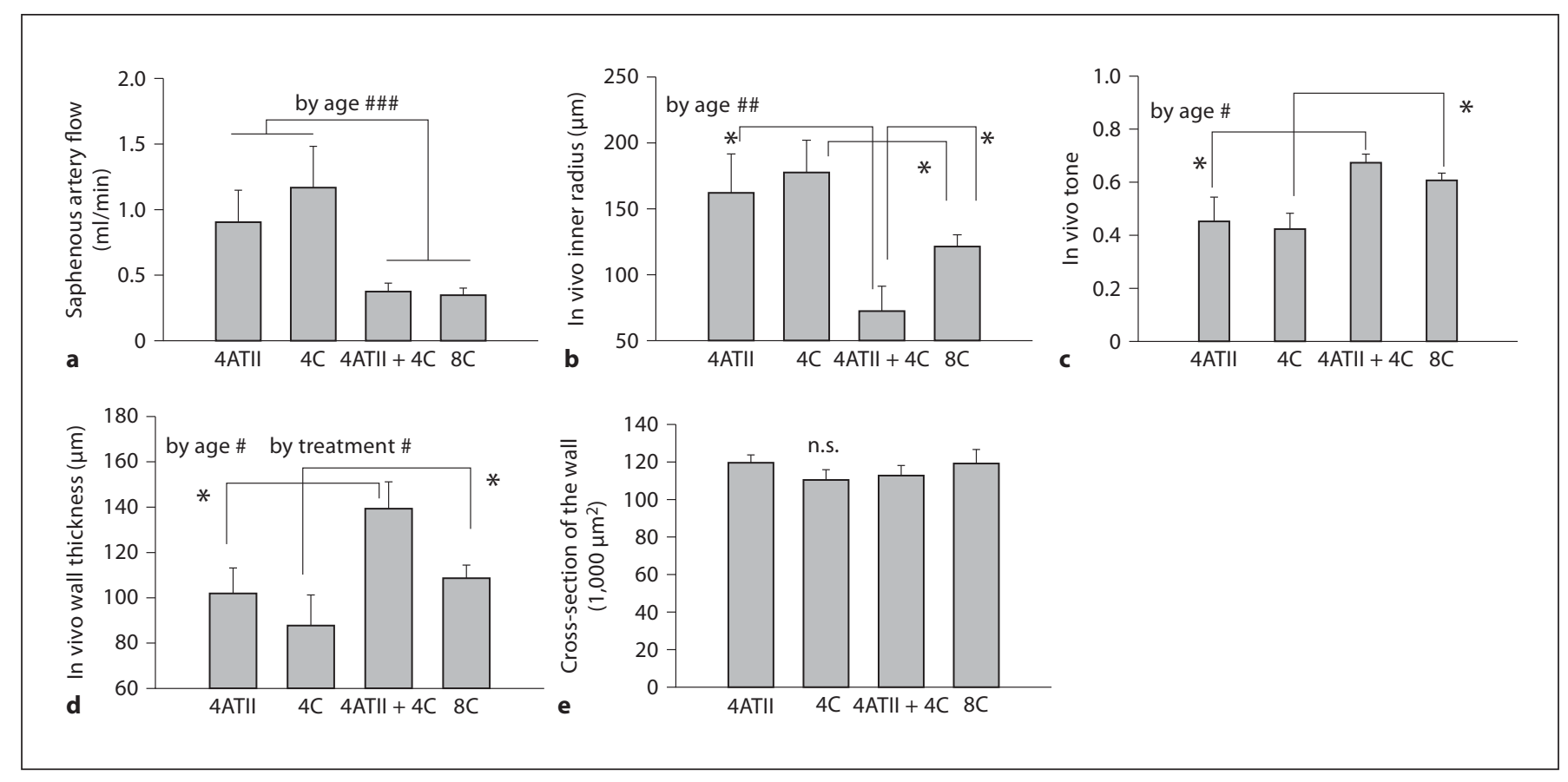

Fig. 2. Local hemodynamics of the saphenous artery branch. Alterations with ATII-induced hypertension and subsequent recovery. $\mathbf{a}$ Blood flow of the saphenous artery. $\mathbf{b}$ In vivo inner radius. $\mathbf{c}$ In vivo tone. $\mathbf{d}$ In vivo wall thickness. e Cross-section of the wall (characterizing wall mass). ${ }^{*} \mathrm{p}<0.05$ (1-way ANOVA); ${ }^{\#} \mathrm{p}<0.05 ;{ }^{\# \#} \mathrm{p}<$ $0.01 ;{ }^{\# \#} \mathrm{p}<0.001$ (2-way ANOVA).

vivo tone during the recovery process $(\mathrm{p}<0.05)$. In $4 \mathrm{ATII}+4 \mathrm{C}$ animals, values as high as $81 \pm 5 \%$ could be measured, which is significantly higher than in their agematched counterparts $(61 \pm 3 \%, \mathrm{p}<0.001)$.

Both age and ATII treatment induced a significant elevation of in vivo measured values of wall thickness (fig. 2d, p < 0.05).

The eutrophic character of all these segmental geometrical changes is reflected in the fact that differences in the cross-sections of the wall did not reach a level of statistical significance in any of the comparisons (fig. 2e).

\section{Passive (Morphological) Segmental Geometry}

Figure 3 shows that ATII infusion induced a reduction in the relaxed inner radius, an increase in wall thickness of relaxed segments, and a consequent reduction in the tangential wall stress as a function of intraluminal pressure $(\mathrm{p}<0.01)$. Somewhat similar alterations characterized the age-induced remodeling of the control non-infused segments. In previously ATII-infused animals, however, the age-induced wall alterations were modified, the relaxed morphological lumen distended, the relaxed wall thickness decreased, and the tangential stress increased $(\mathrm{p}<0.01)$.

\section{Segmental Elasticity}

Elastic modulus as a function of tangential stress was elevated by ATII infusion (fig. $4 \mathrm{c}, \mathrm{p}<0.01$ ). The isobaric distensibility was reduced $(p<0.05)$ and the isobaric elastic modulus was elevated $(\mathrm{p}<0.01)$ in the originally ATII-infused specimens when compared with their agematched counterparts.

\section{Segmental Contractility and Endothelial Dilation}

Both ATII infusion and aging reduced the maximum contractions of the segments in response to norepinephrine (fig. 5b). An overshoot was observed during the recovery period, and the originally hypertensive segments were contracting more vigorously. In vitro spontaneous tone was elevated in ATII-treated segments, and this difference was maintained after 4 weeks of recovery (fig. 5a). Finally, the endothelium-dependent vasodilation was reduced both by hypertension and by aging, and not much recovery could be detected (fig. 5c). 
Fig. 3. Geometry of saphenous artery branch segments. Alterations with ATIIinduced hypertension and recovery measured by in vitro pressure arteriography in the passive state. a Inner radius. b Wall thickness. c Tangential wall stress. $\bullet=4$ weeks' ATII infusion; $\bigcirc=$ sham-operated controls at 4 weeks; $\mathbf{\square}=4$ weeks' ATII infusion + 4-week control period; $\square=$ shamoperated controls at 8 weeks. ATII-treated vs. untreated: \#\# $\mathrm{p}<0.01$; \#\#\# $\mathrm{p}<0.001$ (2-way ANOVA). Compared with 4 weeks earlier (same group): ${ }^{+\dagger} \mathrm{p}<0.01{ }^{{ }^{+\dagger \dagger}} \mathrm{p}<$ 0.001 (2-way ANOVA).

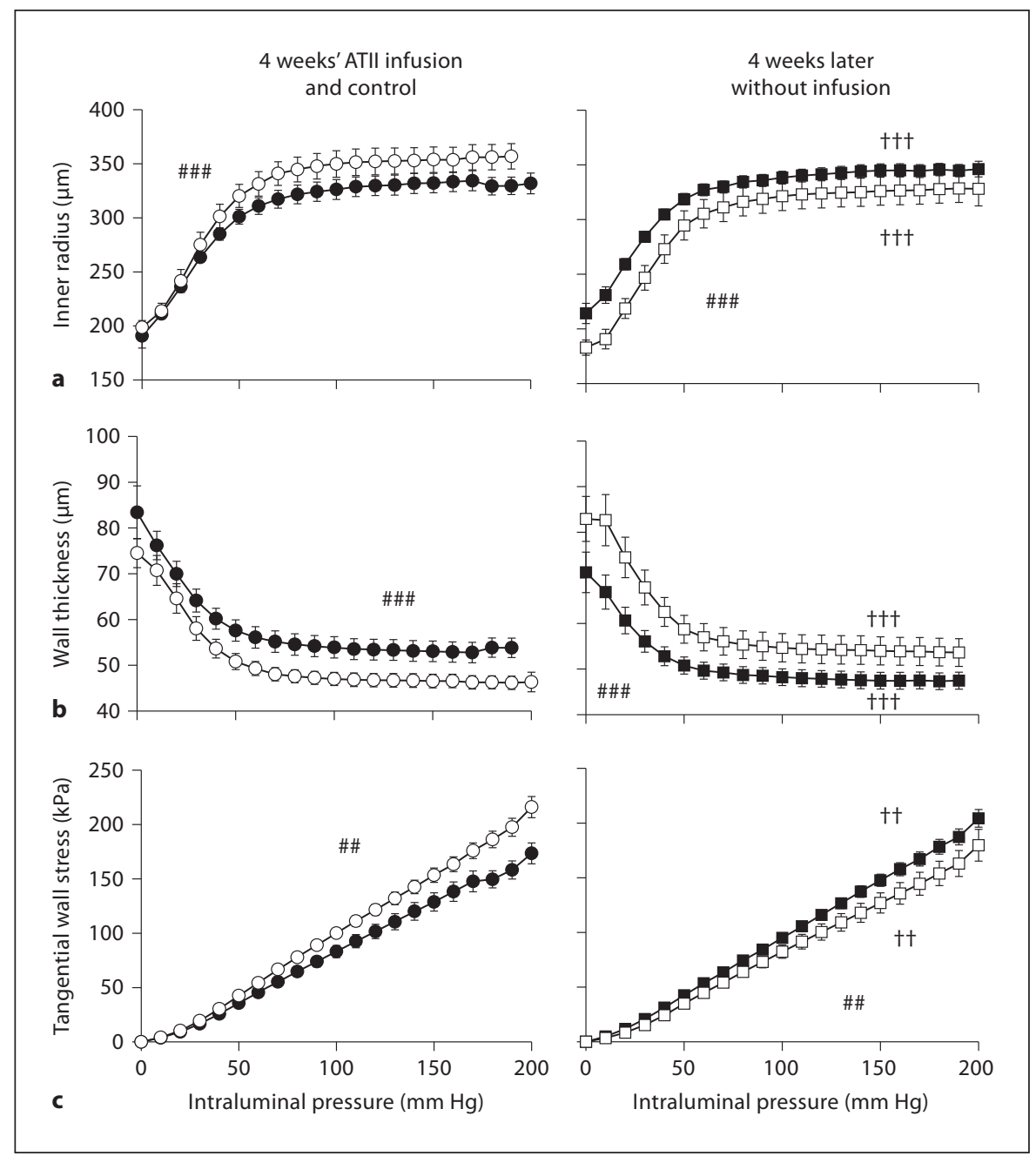

Interdependence of Systemic and Local

Hemodynamics with Segmental Biomechanical

Properties

The body weight of the animals directly correlated with mean arterial pressure, saphenous artery regional flow resistance, in vivo tone measured in the resting anesthetized state, and in vivo wall thickness of the segment, while an inverse correlation with regional flow and in vivo radius was observed (table 1). Systemic arterial pressure positively correlated with total and regional hemodynamic resistance and a negative correlation with regional flow was found. Cardiac output correlated negatively with systemic peripheral resistance.

Saphenous artery flow, in addition to the negative correlations with body weight and systemic arterial blood pressure mentioned previously, correlated negatively with regional flow resistance, in vivo measured wall thickness, and in vivo tone of the segment. Its positive correlations with in vivo lumen and in vivo wall stress could also be verified. Saphenous artery regional resistance negatively correlated with regional flow, while other correlations were the inverse of those found for the saphenous artery flow. In vivo lumen diameter negatively correlated with saphenous artery flow and positively with its regional flow resistance. Positive correlations between in vivo and relaxed geometry prove the impact of morphological remodeling on the in vivo situation. The negative correlation between relaxed inner radius and relaxed wall thickness is characteristic of the eutrophic type of hypertensive morphological remodeling. In vivo tone of this resistance artery increased with body mass, and it was an important determinant of in vivo geometry and played a part in controlling regional vascular resistance and blood flow. Increased systolic and diastolic 
Fig. 4. Elasticity of saphenous artery branch segments. Alterations with ATIIinduced hypertension and with its recovery measured by in vitro pressure arteriography in the passive state. a Incremental distensibility. b log incremental elastic modulus. c log incremental elastic modulus plotted against tangential stress. $\bullet=4$ weeks' ATII infusion; $\bigcirc=$ sham-operated controls at 4 weeks; $\mathbf{\square}=4$ weeks' ATII infusion + 4-week control period; $\square=$ shamoperated controls at 8 weeks. ATII-treated vs. untreated: ${ }^{\#}$ p $<0.05$; ${ }^{\# \#}$ p $<0.01$ (2-way ANOVA). Compared with 4 weeks earlier (same group): ${ }^{++\dagger} \mathrm{p}<0.001$ (2-way ANOVA).

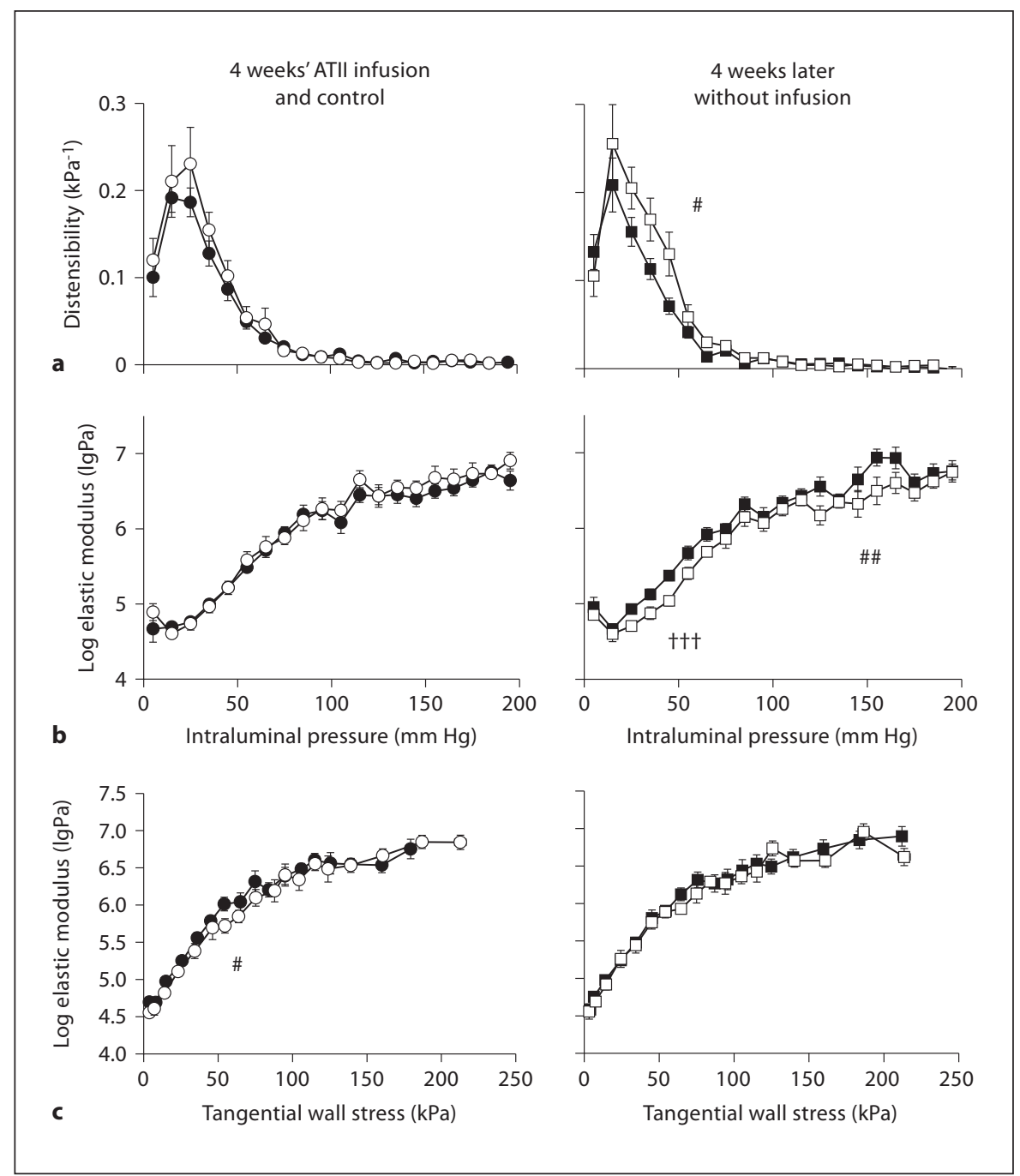

pressures were accompanied by reduced elastic modulus in the high pressure range. Morphologically narrowed segments produced less active contraction in vitro. Endothelial relaxation negatively correlated with systolic and diastolic blood pressure.

\section{Discussion}

The interdependence of systemic and local hemodynamics with segmental biomechanical properties in a resistance artery was studied in hypertension and its subsequent recovery. Hypertension was induced by the chronic infusion of ATII (150 ng/min/ $/ \mathrm{kg})$. This caused morphological narrowing with proportional elevation in morphological wall thickness (eutrophic remodeling).
Four weeks after cessation of the drug infusion, the morphological narrowing healed fully, but a persistent and more vigorous contractility kept the in vivo lumen reduced and local hemodynamic resistance elevated.

\section{Biomechanics of Eutrophic Hypertensive Vascular Wall Remodeling}

A morphologically stable small musculocutaneous artery segment with an in vivo lumen diameter (resting anesthetized animals) around $350 \mu \mathrm{m}$ was studied. Such arteries are in the resistance artery range [45]. A 4-week ATII infusion (150 ng/min/kg) induced a significant elevation in arterial blood pressure values, as described earlier (fig. 1a) [37, 40, 41]. The segments underwent a typical eutrophic hypertensive remodeling $[2,4,8,9]$ characterized by a reduction in relaxed (morphological) 
Fig. 5. Contractility of saphenous artery segments. Alterations from ATII-induced hypertension and subsequent recovery measured by in vitro pressure arteriography. a Spontaneous tone in normal KrebsRinger solution. $\mathbf{b}$ Tone induced by maximum concentration $(10 \mu \mathrm{mol} / \mathrm{l})$ of norepinephrine (NE). c Endothelial relaxation tested with $10 \mu \mathrm{mol} / \mathrm{l}$ acetylcholine. $\bullet=4$ weeks' ATII infusion; $\bigcirc=$ sham-operated controls at 4 weeks; $\mathbf{\square}=4$ weeks' ATII infusion + 4-week control period; $\square=$ shamoperated controls at 8 weeks. ATII-treated vs. untreated: ${ }^{\#} \mathrm{p}<0.05 ;{ }^{\# \#} \mathrm{p}<0.01 ;{ }^{\# \#} \mathrm{p}<$ 0.001 (2-way ANOVA). Compared with 4 weeks earlier (same group): ${ }^{\dagger \dagger} \mathrm{p}<0.01$; ${ }^{\dagger+\dagger} \mathrm{p}<0.001$ (2-way ANOVA).

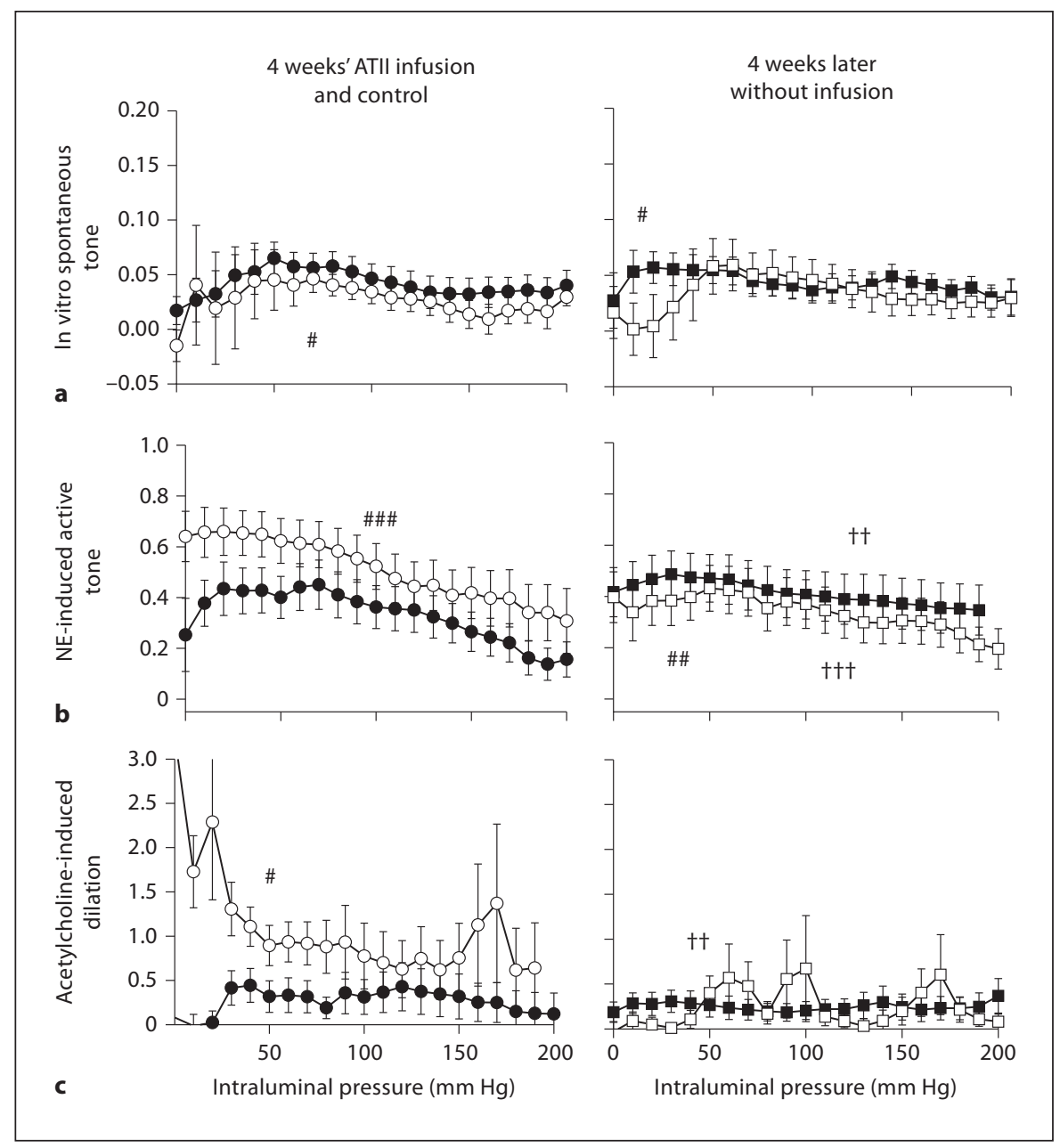

outer and inner radii and increased wall thickness (fig. 2a, b), with no significant alteration in wall mass (fig. 2e). These geometrical changes induced a substantial reduction in tangential wall stress measured at the same pressures (fig. 3c). From the diagram, it can be seen that wall stress values measured at in vivo mean arterial pressures (106 and $142 \mathrm{~mm} \mathrm{Hg}$, for control and hypertensive animals, respectively) remained practically unaltered. Hypertensive wall remodeling thus seemed to stabilize in vivo stress during hypertension, as has been suggested previously $[1-3,19,46]$. A portion of the elastic alterations observed can be a consequence of changes in segmental geometry (fig. 4a, b). There was, however, some authentic alteration in the elastic properties of the wall material itself. The elevation we found in elastic modulus as a function of wall stress in the low stress range (fig. 4c) is characteristic of elevated elastin production [21, 22, 30, 47]. Similar wall elasticity changes in other types of sustained hypertension have been described previously $[1,5,10,17-$ $22,48]$. There was also a significant change in the active biomechanical behavior of the segments. Maximum contraction with norepinephrine was reduced, as was the extent of endothelial dilation (fig. 5). The study group of Simon found an elevated sensitivity to sympathetic stimulation in the mesenteric microvascular bed in a similar animal model [23]. In human essential hypertension, subcutaneous resistance vessels prepared from fat tissue had an increased sensitivity to norepinephrine [7]. Reduced spontaneous tone was reported from cremaster muscle resistance vessels of high salt-reduced renal mass hypertensive rats [24]. Thus, microvascular contractility changes may depend on the type and duration of hypertension, caliber, and anatomical location. The reduced endothelial dilation that we have found is in accord with other publications $[6,8,25]$. Our combined in vitro and in vivo studies confirmed that the in vivo lumen was 
Table 1. Interconnection of systemic and local hemodynamics with segmental geometry of the saphenous artery branch of the rat during ATII-induced hypertension and subsequent recovery

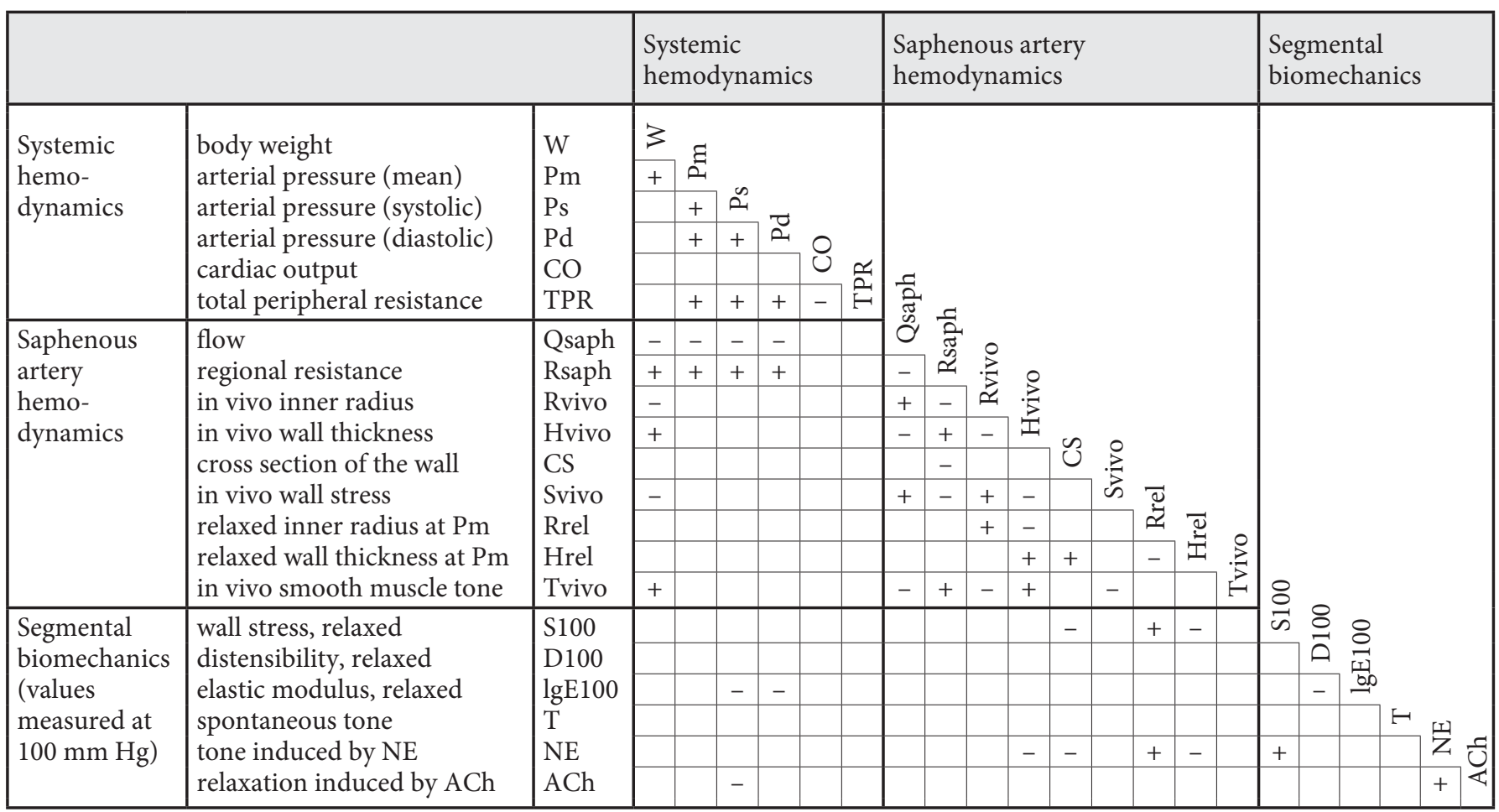

Positive (+) and negative (-) Pearson correlations at $\mathrm{p}<0.05$ are shown. NE $=$ Norepinephrine; ACh $=$ acetylcholine.

mostly determined by the substantial in vivo tone in these vessels (fig. 2c). Effective local control mechanisms ensured unaltered local tissue flow (fig. 2a) despite elevated blood pressure.

The sensitive biomechanical tests used suggested that the hypertensive eutrophic wall remodeling might have developed simply as a morphological stabilization of a partially contracted state of the segment. Newly formed extracellular connective tissue $[5,21]$ or intracellular alterations in vascular smooth muscle cytoskeletal scaffolding could clamp the relaxed circumference at a somewhat shortened contracted length. That single fact could explain the reduced morphological radius, the increased morphological wall thickness, the eutrophy of the wall mass, the reduced extent of maximum contraction, and even the somewhat elevated stress-dependent elastic modulus. This approach is in accordance with the theory of eutrophic hypertensive wall remodeling as described recently by Rizzoni and Agabiti-Rosei [49]. A somewhat similar mechanism has been suggested in a recent human study by the Mulvany group [50]. They found that hypertensive lumen narrowing of resistance arteries and their dilation during therapy is best explained by stabilization of flow-induced lumen alterations.

Another interesting observation was the analogy of the hypertensive remodeling of the vascular wall with the remodeling induced by aging of the animals. Resistance artery segments from 16-week-old rats without any hypertensive treatment had reduced relaxed morphological diameters, increased relaxed wall thickness, reduced contractility, and reduced endothelial dilation compared with 12-week-old non-infused rats; these alterations resembled those of 12 -week-old rats that had been infused between 8 and 12 weeks with pressor doses of ATII.

\section{Regression of Hypertensive Vascular Wall \\ Remodeling}

Animals subjected to 4 weeks of ATII infusion had significantly higher total peripheral resistance, even after an additional 4-week recovery, than their age-matched counterparts (fig. 1c). There was no significant difference in blood pressure (fig. 1a), as cardiac output did not increase as it did in control animals (fig. 1b). At the end 
of the 4-week recovery period, the originally hypertensive small artery segments were not only geometrically similar to their age-matched counterparts, but even some overcompensation of the relaxed lumen could be observed (fig. 3a, b). Despite recovery of the elastic properties of the wall material (fig. 4c), the altered geometry caused a somewhat reduced isobaric distensibility and elevated isobaric elastic modulus (fig. $4 \mathrm{a}, \mathrm{b}$ ). One possible explanation for these events is that decreasing pressures with cessation of ATII infusion reduced wall stress. A different explanation is that without the continuous effect of external ATII, the stimulus for the morphological rearrangement of the smooth muscle will be reversed. There was an overcompensation of contractility: both the spontaneous tone and the norepinephrine-induced maximum contractions were substantially elevated (fig. 5a, b). This increased contractility can not be explained alone by a reduced level of endothelial dilation, as acetylcholine-induced dilation was also reduced in the control aged group (fig. 5c). Our observation proves that the trophic effects of ATII on vascular smooth muscle contractile protein production [41-44, 48, 51] can appear even several weeks after the cessation of drug delivery. From a hemodynamic point of view, however, it was decisive that the in vivo lumen of previously hypertensive animals was significantly smaller than that of their agematched counterparts (fig. $2 b$ ) as a result of a higher in vivo tone (fig. 2c).

Our study confirms earlier reports that hypertensive remodeling of resistance arteries is a partially reversible process. Improvement in the elevated wall thickness/lumen ratio was found by histology and arteriography [4, $6-8,11,13,15,32,35]$. Attenuated contractile responses $[13,24,52]$ and impaired endothelial dilations $[53,54]$ were found to recover, and small artery elasticity improved [20,36]. Hydralazine treatment reduced elastin accumulation [29], and ACE treatment reduced collagen/ elastin ratio in spontaneously hypertensive rats [8]. In vivo observable dilation with antihypertensive treatment was described in retinal [12], muscle [24] and coronary [38] resistance arteries, which is in contrast to our observations. Angiotensin-converting enzyme blockers proved to be more effective to treat hypertensive wall alterations than other therapies $[7,13,55]$. These findings underscore the significance of the endogenous ATII system with its trophic effect on the resistance artery wall $[12,40-44,51]$. The diverse intracellular mechanisms potentially involved have already been surveyed in [44, 51].

\section{Interdependence of Systemic and Local} Hemodynamics and Segmental Vascular Wall Mechanics

Our data are in accord with earlier observations that increasing body weight is not accompanied by a parallel reduction in systemic and regional hemodynamic resistance $[55,56]$. Effectiveness of blood pressure control is shown by the fact that cardiac output correlated negatively with systemic peripheral resistance. Our data demonstrate that musculocutaneous arteries of this range (control resting calibers $355 \pm 50$ micrometers) actively cooperate in systemic blood pressure control processes. In vivo tone of this resistance artery increased with body mass, and it was an important determinant of in vivo geometry, regional vascular resistance and regional blood flow. However, alterations in the more peripheral resistance arteries, with their profound network changes [26, $27,57]$, might have been even more important. Increased systolic and diastolic pressures were accompanied by a reduced elastic modulus in the high-pressure range, a typical alteration when elastin is accumulated in the wall $[30,47]$. Morphologically narrowed segments produced less active contraction in vitro. This is in accordance with our assumption described above that during eutrophic remodeling segments might be 'clamped' in a slightly contracted state. The inverse correlation of endothelial relaxation with systolic and diastolic blood pressure confirms earlier reports $[6,8,25]$.

\section{Conclusion}

Chronic ATII infusion induced a eutrophic hypertensive remodeling of a musculocutaneous small artery (inner diameter around $350 \mu \mathrm{m}$ ) with reduced relaxed morphological lumen, increased relaxed wall thickness, reduced contractility, reduced endothelial dilation, and reduced low-stress elasticity. One plausible explanation could be a morphological stabilization of the vessel in a slightly contracted state (contraction clamp). Small arteries remodeled by hypertension resemble those found in somewhat older animals with increased body mass (accelerated aging). Following a 4 -week recovery period, alterations in relaxed segmental geometry were reversed, and contractility rose above control values. Despite recovered morphological geometry, the in vivo lumen of the segment remained reduced (partial recovery). The recovery from hypertensive remodeling was not just a simple reversal of its development. 


\section{Acknowledgements}

This study was funded by grants from the Hungarian National Scientific Foundation (OTKA TO 32019, OTKA TO 30245, OTKA TO 42670, and OTKA TO 37832), the Health Science
Council of Hungary (ETT 128/2006), the Hungarian Space Agency (BO 00080/03), the Hungarian Society of Hypertension and the Hungarian Kidney Foundation. The expert technical assistance of Ms. Ildikó Oravecz and Ms. Katalin Juhász is appreciated.

\section{References}

1 Folkow B: 'Structural factor' in primary and secondary hypertension. Hypertension 1990;16:89-101.

$\checkmark 2$ Mulvany MJ: The development and regression of vascular hypertrophy. J Cardiovasc Pharmacol 1992;19(suppl 2):S22-S27.

$\checkmark 3$ Folkow B: Hypertensive structural changes in systemic precapillary resistance vessels: how important are they for in vivo haemodynamics? J Hypertens 1995;13:1546-1559.

4 Mulvany MJ: Effects of angiotensin converting enzyme inhibition on vascular remodeling of resistance vessels in hypertensive patients. J Hypertens 1996;14(suppl 6):S21S24.

5 Laurant P, Touyz RM, Schiffrin EL: Effect of pressurization on mechanical properties of mesenteric small arteries from spontaneously hypertensive rats. J Vasc Res 1997;34:117125.

-6 Li JS, Sharifi AM, Schiffrin EL: Effect of AT1 angiotensin-receptor blockade on structure and function of small arteries in SHR. J Cardiovasc Pharmacol 1997;30:75-83.

7 Safar ME, van Bortel LM, Struijker-Boudier HA: Resistance and conduit arteries following converting enzyme inhibition in hypertension. J Vasc Res 1997;34:67-81.

$>$ Sharifi AM, Li JS, Endemann D, Schiffrin EL: Effects of enalapril and amlodipine on small-artery structure and composition, and on endothelial dysfunction in spontaneously hypertensive rats. J Hypertens 1998;16:457466.

$\checkmark 9$ Colas B, Collin T, Safraou F, Chatelain D, Cordonnier C, Henry X, Safar M, Andrejak M, Slama M: Direct vascular actions of methyclothiazide in remodeled mesenteric arteries from hypertensive patients. Am J Hypertens 2001;14:989-994.

$\checkmark 10$ Intengan HD, Schiffrin EL: Vascular remodeling in hypertension: roles of apoptosis, inflammation, and fibrosis. Hypertension 2001;38:581-587.

- 11 Yokoyama H, Averill DB, Brosnihan KB, Smith RD, Schiffrin EL, Ferrario CM: Role of blood pressure reduction in prevention of cardiac and vascular hypertrophy. Am J Hypertension 2005;18:922-929.

-12 Pose-Reino A, Rodriguez-Fernandez M, Hayik B, Gomez-Ulla F, Carrera-Nouche MJ, Gude-Sampedro F, Estevez-Nunez JC, Mendez-Naya I: Regression of alterations in retinal microcirculation following treatment for arterial hypertension. J Clin Hypertens 2006;8:590-595.
13 Schiffrin EL: Correction of remodeling and function of small arteries in human hypertension by cilazapril, an angiotensin I-converting enzyme inhibitor. J Cardiovasc Pharmacol 1996;27(suppl 2):S13-S18.

14 Illyes G, Talarico PJ, Simon G: Different structural vascular changes in angiotensin II-treated and cold-stressed rats. Am J Hypertens 2000;13:802-809.

15 Kvist S, Mulvany MJ: Contrasting regression of blood pressure and cardiovascular structure in declipped renovascular hypertensive rats. Hypertension 2003;41:540-545.

16 Dickhout JG, Lee RM: Increased medial smooth muscle cell length is responsible for vascular hypertrophy in young hypertensive rats. Am J Physiol Heart Circ Physiol 2000; 279:H2085-H2094.

17 McGuffee LJ, Little SA: Tunica media remodeling in mesenteric arteries of hypertensive rats. Anat Rec 1996;246:279-292.

18 Intengan HD, Schiffrin EL: Mechanical properties of mesenteric resistance arteries from Dahl salt-resistant and salt-sensitive rats: role of endothelin-1. J Hypertens 1998; 16:1907-1912.

19 Szentiványi M, Nádasy GL, Tóth M, Kopcsányi V, Jedrákovits A, Monos E: Biomechanics of the saphenous artery and vein in spontaneous hypertension Pathophysiology 1998;4:295-302.

20 Takeuchi K, Ideishi M, Tashiro T, Morishige N, Yamada T, Saku K, Urata H: Higher small arterial elasticity in hypertensive patients treated with angiotensin II receptor blockers. Hypertens Res 2005,28:639-644.

21 Briones AM, Gonzalez JM, Somoza B, Giraldo J, Daly CJ, Vila E, Gonzalez MC, McGrath JC, Arribas SM: Role of elastin in spontaneously hypertensive rat small mesenteric artery remodelling. J Physiol 2003;552:185195.

22 Gonzalez JM, Briones AM, Somoza B, Daly CJ, Vila E, Starcher B, McGrath JC, Gonzalez MC, Arribas SM: Postnatal alterations in elastic fiber organization precede resistance artery narrowing in SHR. Am J Physiol Heart Circ Physiol 2006;291:H804-H812.

23 Cserep G, Abraham G, Tolins JP, Simon G: Different vascular responses to subpressor angiotensin II administration in the mesenteric and renal circulation of rats. Am J Hypertens 1996;9:385-392.
24 Frisbee JC, Lombard JH: Development and reversibility of altered skeletal muscle arteriolar structure and reactivity with high salt diet and reduced renal mass hypertension. Microcirculation 1999;6:215-225.

25 James MA, Tullett J, Hemsley AG, Shore AC: Effects of aging and hypertension on the microcirculation. Hypertension 2006;47:968974.

26 Rodriguez-Porcel M, Zhu XY, Chade AR, Amores-Arriaga B, Caplice NM, Ritman EL, Lerman A, Lerman LO: Functional and structural remodeling of the myocardial microvasculature in early experimental hypertension. Am J Physiol Heart Circ Physiol 2006;290:H978-H984.

-27 Prasad A, Dunhill GS, Mortimer PS, MacGregor GA: Capillary rarefaction in the forearm skin in essential hypertension. J Hypertens 1995;13:265-268.

28 Pries AR, Reglin B, Secomb TW: Remodeling of blood vessels: responses of diameter and wall thickness to hemodynamic and metabolic stimuli. Hypertension 2005;46: 725-731.

29 Hajdu MA, Heistad DD, Ghoneim A, Baumbach GL: Effects of antihypertensive treatment on composition of cerebral arterioles. Hypertension 1991;18(suppl):II15-II21.

30 Cox RH, Bagshaw RJ: Effects of hypertension and its reversal on canine arterial wall properties. Hypertension 1988;12:301-309.

31 Levy BI, Michel JB, Salzmann JL, Azizi M, Poitevin P, Safar M, Camilleri JP: Effects of chronic inhibition of converting enzyme on mechanical and structural properties of arteries in rat renovascular hypertension. Circ Res 1988;63:227-239.

32 Heagerty AM, Bund SI, Aalkjaer C: Effects of drug treatment on human resistance arteriole morphology in essential hypertension: direct evidence for structural remodelling of resistance vessels. Lancet 1988;2:12091212 .

33 Giummelly P, Lartaud-Idjouadiene I, Marque V, Niederhoffer N, Chillon JM, CapdevilleAtkinson C, Atkinson J: Effects of aging and antihypertensive treatment on aortic internal diameter in spontaneously hypertensive rats. Hypertension 1999;34:207-211.

34 Stacy DL, Prewitt RL: Effects of chronic hypertension and its reversal on arteries and arterioles. Circ Res 1989;65:869-879. 
-35 Thybo NK, Korsgaard N, Eriksen S, Christensen KL, Mulvany MJ: Dose-dependent effects of perindopril on blood pressure and small artery structure. Hypertension 1994; 23:659-666.

-36 Savoia C, Touyz RM, Amiri F, Schiffrin EL: Selective mineralocorticoid receptor blocker eplerenone reduces resistance artery stiffness in hypertensive patients. Hypertension 2008;51:432-439.

\37 Várbiró S, Nádasy GL, Monos E, Vajo Z, Ács N, Miklós Z, Tőkés A, Székács B: Effect of ovariectomy and hormone replacement therapy on small artery biomechanics in angiotensin-induced hypertension in rats. J Hypertension 2000;18:1587-1595.

-38 Vogt M, Strauer BE: Response of hypertensive left ventricular hypertrophy and coronary microvascular disease to calcium antagonists. Am J Cardiol 1995;76:24D-30D.

39 Nádasy GL, Monos E: Biomechanical principles of vascular wall design in health and in disease: some mathematics of angiogenesis. Acta Phsiol Hung 2007;94:377-379.

40 Simon G, Abraham G, Altman S: Stimulation of vascular glycosaminoglycan synthesis by subpressor angiotensin II in rats. Hypertension 1994;23(1 suppl):I148-I151.

-41 Simon G, Abraham G, Cserep G: Pressor and subpressor angiotensin II administration: two experimental models of hypertension. Am J Hypertension 1995;8:645-650.
42 Griffin SA, Brown WC, Macpherson F, McGrath JC, Wilson WG, Korsgaard N, Mulvany MJ, Lever AF: Angiotensin II causes vascular hypertrophy in part by a non-pressor mechanism. Hypertension 1991;17:626635.

43 Simon G, Illyes G, Csiky B: Structural vascular changes in hypertension: role of angiotensin II, dietary sodium supplementation, blood pressure, and time. Hypertension 1998;32:654-660.

44 Touyz RM: Intracellular mechanisms involved in vascular remodelling of resistance arteries in hypertension: role of angiotensin II. Exp Physiol 2005;90:449-455.

45 Mulvany MJ, Aalkjer C: Structure and function of small arteries. Physiol Rev 1990;70: 921-961.

46 Rodbard S: Vascular caliber. Cardiology 1975;60:4-49.

47 Dobrin PB: Mechanical properties of arteries. Physiol Rev 1978;58:397-460.

48 Baumbach GL, Sigmund CD, Faraci FM: Cerebral arteriolar structure in mice overexpressing human renin and angiotensinogen. Hypertension 2003;41:50-55.

$\checkmark 49$ Rizzoni D, Agabiti-Rosei E: Small artery remodeling in hypertension and diabetes. Curr Hypert Rep 2006;8:90-95.

50 Mathiasen ON, Buus N, Larsen ML, Mulvany MJ, Christensen KL: Small artery structure adapts to vasodilation rather than to blood pressure during antihypertensive treatment. J Hypert 2007;25:1027-1034.
51 Hunyady L, Catt KJ: Pleiotropic $\mathrm{AT}_{1}$ receptor signaling pathways mediating physiological and pathogenic actions of angiotensin II. Mol Endocrinol 2006;20:953-970.

52 Toyoda K, Fujii K, Ibayashi S, Kitazono T, Nagao T, Takaba H, Fujishima M: Attenuation and recovery of brain stem autoregulation in spontaneously hypertensive rats. J Cerebr Blood Flow Metabol 1998;18:305310.

53 Heistad DD, Armstrong ML, Baumbach GL, Faraci FM: Sick vessel syndrome: recovery of atherosclerotic and hypertensive vessels. Hypertension 1995;26:509-513.

54 Landsberg L, Krieger DR: Obesity, metabolism and the sympathetic nervous system. Am J Hypertension 1989;2:1255-1325.

55 Schiffrin EL, Deng LY, Larochelle P: Effects of antihypertensive treatment on vascular remodeling in essential hypertensive patients. J Cardiovasc Pharmacol 1994;24(suppl 3):S51-S56.

56 Hall JR: The kidney, hypertension and obesity. Hypertension 2003;41:625-633.

57 Nádasy GL, Várbíró S, Ács N, Székács B, Loránt M, Jackel M, Kerényi T, Monos E: Intramural coronary resistance artery network remodeling in chronically angiotensin II-infused female rats. J Physiol (London) 2000; 526(suppl S):133P. 